\title{
Predição para o índice de qualidade ambiental de municípios cearenses consorciados
}

A gestão ambiental no Brasil tem recorrido cada vez mais aos instrumentos de base econômica para promover a melhoria do desempenho ambiental. Em 2008 , 0 Estado do Ceará adotou o ICMS Ecológico, no qual incluiu o Gerenciamento de Resíduos Sólidos Urbanos como critério de repasse desse tributo aos municípios tomando como base a nota obtida pelo município no Índice de Qualidade Ambiental (IQM). Este artigo tem como objetivo estimar a nota do IQM para 11 municípios do Consórcio de Gestão Integrada de Resíduos Sólidos do Vale do Jaguaribe (CGIRS-VJ), utilizando a série histórica das notas compreendidas entre os anos de 2009 a 2017, obtidas mediante dados coletados pelo Formulário 18. Modelos de regressão KNM foram estimados e previsões do IQM foram feitas para o horizonte temporal de 30 anos, a contar de 2018. Os resultados apontaram que as previsões das notas variam entre 0,2 e 0,6, o que indica que, caso os critérios de análise fossem mantidos, para o futuro, nenhum município da região alcançaria a nota máxima $(1,0)$, a não ser por meio de intervenção externa.

Palavras-chave: ICMS Ecológico; Consórcio Intermunicipal; Resíduos Sólidos.

\section{Prediction of environmental quality index of the consorted towns from Ceará}

The environmental management in Brazil has relied increasingly in the economic based instruments for promoting the improvement of the environmenta performance. In 2008, the state of Ceará adopted the Ecological ICMS, in which included the Urban Solid Waste Management as a criterion to transfer this tribute to municipalities, taken as basis the grades obtained by the municipality in the Environmental Quality Index (IQM). This paper aims to calculate the IQM to eleven municipalities of the Consortium of Solid Waste Integrated Management Jaguaribe Valley (CGIRS-VJ). Using data collected by the Form 18, regression models of KNM were used to make IOM predictions for the municipalities during 30 years. The results pointed out that, if the actual conditions were maintained during the period, no municipality of the region would achieved the maximum grade $(1,0)$, unless thought out external intervention such as implanting the consortium and using the Form IQM 18-A

Keywords: Ecological ICMS; Intermunicipal Consortium; Solid Waste.

Reviewed anonymously in the process of blind peer.

Carlos Vangerre de Almeida Maia (ID) Universidade Federal do Piauí, Brasil http://lattes.cnpq.br/8382619280144808 http://orcid.org/0000-0002-4800-5404 cvamaia@yahoo.com.br

Rogério César Pereira de Araújo Universidade Federal do Ceará, Brasil http://lattes.cnpq.br/2048684813061911 http://orcid.org/0000-0002-5716-3236 rcpa@ufc.br

Anny Kariny Feitosa

Instituto Federal do Ceará, Brasil http://lattes.cnpq.br/6604861578850716 http://orcid org/0000-0002-5745-2660 akfeitosa@hotmail.com
Anna Ariane de Araujo Lavor (D) Instituto Federal do Ceará, Brasil http://lattes.cnpq.br/375683419648246 http://orcid.org/0000-0001-5729-0270 annaariane@hotmail.com

Antônio Carlos Alves da Silva

Universidade do Vale do Taquari, Brasil http://lattes.cnpq.br/8290289229062502 http://orcid.org/0000-0001-9685-9490 acas-acas@hotmail.com

Amanda Ferreira Dias

Universidade Estadual do Ceará, Brasil http://lattes.cnpq.br/6766032597051302 http://orcid.org/0000-0002-9352-2849 fdiasamanda@gmail.com
Alecvan de França Souza Instituto Federal do Ceará, Brasil http://lattes.cnpq.br/2651954659980966 http://orcid.org/0000-0002-1143-5670 alecvan.sousa@ifce.edu.br

\section{Referencing this:}

MAIA, C. V. A.; ARAÚJO, R. C. P.; FEITOSA, A. K.; LAVOR, A. A. A.; SILVA A. C. A.; DIAS, A. F.; SOUSA, A. F.. Predição para o índice de qualidade ambiental de municípios cearenses consorciados. Nature and Conservation, v.13, n.4, p.93-103, 2020. DOI: http://doi.org/10.6008/CBPC2318-2881.2020.004.0011 


\section{INTRODUÇÃO}

O Imposto sobre Operações Relativas à Circulação de Mercadorias e sobre Prestação de Serviços de Transporte Interestadual e Intermunicipal e de Comunicação (ICMS) teve sua origem no inciso II do artigo 155 da Constituição Federal de 1988. É de competência estadual e representa cerca de $80 \%$ da arrecadação dos estados (SEBBAG, 2014).

De acordo com Silva Junior et al. (2014) e Ferreira et al. (2017), a Constituição Federal (art. 158/II) determina que os Estados devam repassar 25\% da arrecadação do ICMS aos municípios, sendo que desse montante, 75\% (18,75\% do total), no mínimo, deva ser rateado em função do Valor Adicionado Fiscal (VAF), enquanto que, no máximo $25 \%$ da quota-parte municipal (6,25\% do todo), no máximo, deva ser distribuído segundo critérios definidos pela legislação de cada Estado.

Dentre as modalidades de tributação brasileira, a extrafiscalidade tem como objetivo intervir na estrutura social e/ou econômica, podendo a mesma estimular ou coibir os atores sociais (entes privados ou públicos), mediante externalidades (positiva ou negativa).

No setor ambiental, a tributação extrafiscal busca promover o bem comum - condição mormente posta a partir dos anos 30 do último século - perpassando o caráter arrecadatório exclusivo e enfatizando a função de estimular ou desestimular certas condutas, de tal forma a garantir e ampliar o princípio da dignidade humana (COSTA et al., 2016).

Nesse contexto, Rolim et al. (2013) afirmam que a tributação ambiental possibilita assegurar parcela da arrecadação de determinado tributo à preservação do meio ambiente, constituindo-se em um instrumento econômico indutor à qualidade ambiental.

No Brasil, apesar da inexistência de tributação vinculada à proteção ambiental, mecanismos tributários distributivos têm sido concebidos para este fim. Em 1991, no Paraná, aplicando o princípio do Protetor-Recebedor, Estado e municípios acordaram destinar uma parcela do ICMS àqueles municípios que desenvolviam ações de proteção das Unidades de Conservação ambiental e dos mananciais de abastecimento, como compensação. Essa política, posteriormente, recebeu a denominação de ICMS Ecológico (CARNEIRO et al., 2018).

No Nordeste, Pernambuco foi o primeiro Estado a instituir o ICMS Ecológico, por meio da Lei Estadual no $11.899 / 2000$. Um dos critérios para o repasse dos valores aos municípios é a implementação de sistemas de tratamento de resíduos sólidos (com o consequente encerramento dos lixões), além da manutenção de unidades de conservação (CONCEIÇÃO et al., 2010; SILVA JUNIOR et al., 2014).

Em 2008, o Ceará instituiu o ICMS Socioambiental ${ }^{1}$, através do Decreto $n^{\circ}$ 29.306/2008, determinando que o Índice Municipal de Qualidade do Meio Ambiente (IQM) seria o critério de repasse da parcela do tributo (CEARÁ, 2008).

${ }^{1}$ O IQM não é um novo tributo, nem uma majoração da alíquota do ICMS, mas a uma possibilidade de maximização do repasse da cota parte em virtude da preocupação e investimento dos municípios em prol da preservação ambiental. Sendo, um instrumento com características de incentivo positivo e não-coercitivo, desempenhando o corporativismo do federalismo fiscal, podendo, inclusive, ser compreendido como um instrumento inerente ao Princípio do Protetor Recebedor (TAKENAKA et al., 2016; LIMA et al., 2019; TUPIASSU et al., 2019). 
O IQM é um programa que avalia a implantação do Plano de Gerenciamento Integrado de Resíduos Sólidos (PGIRSU) local. Os municípios se inscrevem e preenchem um Formulário de Coleta de Dados (Formulário), que permite pontuação gradativa, variando de zero a um, e enviam documentação comprobatória.

Em 2017, o Decreto $n^{\circ} 32.482$ alterou o Decreto $n^{\circ} 29.306 / 2008$, possibilitando que os municípios entes de algum Consórcio Intermunicipal de Gestão Resíduos Sólidos possam facultar o envio das informações não mais pelo Formulário 18, sim pelo Formulário 18-A (CEARÁ, 2017), que não mais apresenta caráter gradativo para os índices; sim, binário - ou nota máxima $(1,0)$, ou nota mínima $(0,0)$.

Nesse sentido, faz-se imperativo avaliar o impacto da mudança da alteração do Formulário de coleta de dados em municípios consorciados, para que seja possível estimar as notas desses municípios ao longo de um período determinado. Tem-se por hipótese que, caso as condições pretéritas de análise fossem mantidas, municípios não consorciados, por consequência, não teriam possibilidade de atingir a nota máxima do IQM.

Logo, objetiva-se estimar as notas do IQM para 11 municípios do Consórcio de Gestão Integrada de Resíduos Sólidos do Vale do Jaguaribe (CGIRS-VJ), para os próximos 30 anos, assumindo a tendência apresentada pelas notas recebidas ao longo dos anos 2009 a 2017.

Este artigo está dividido em cinco seções. A primeira contextualizou o problema e enfatizou a necessidade da análise do IQM. Na segunda seção, faz-se o histórico do ICMS Socioambiental e descrevemse os critérios do IQM, bem como são traçados conectivos entre o IQM e a Política Estadual de Resíduos Sólidos (PERS). A terceira descreve a área de estudo, os dados e métodos utilizados. Na quarta, apresentamse os resultados e discussão dos modelos de previsão do IQM. E, finalmente, na quinta seção fazem-se as considerações finais do estudo.

\section{REVISÃO TEÓRICA}

\section{ICMS socioambiental}

Segundo Lima et al. (2019), o Governo do Estado definiu sua primeira metodologia para o rateio da quota-parte municipal do ICMS através da Lei Estadual n 12.612/96 (CEARÁ, 1996), cuja distribuição considerava: a) $75 \%$ referente ao $\mathrm{VAF}$ - conforme $\mathrm{CF} / 88$; b) $5 \%$ pela relação entre a população do município e a população total do estado, conforme dados fornecidos pelo IBGE; c) $12,5 \%$ mediante quociente da relação entre a soma das despesas com educação realizadas pelo município, e soma de todas as receitas do município, com base em dados do segundo ano civil imediatamente anterior, fornecidos pelo Tribunal de Contas dos Municípios; e d) 7,5\% distribuídos igualitariamente entre todos os Municípios.

Essa metodologia foi alterada por meio da Lei № 14.023 de 17 de dezembro de 2007, regulamentada pelos decretos № 29.306, de 05 de junho de 2008, e № 29.586, de 19 de dezembro de 2008. Sob essas normas, $25 \%$ da quota-parte do repasse do ICMS aos municípios, seguiu os seguintes critérios: 18\% da arrecadação estadual, de acordo com o Índice de Qualidade Educacional (IQE); 5\% em função do Índice de Qualidade da Saúde (IQS); e, 2\% em função do Índice Municipal de Qualidade do Meio Ambiente (IQM) 
(CEARÁ, 2007).

Para Nogueira (2012), a forma original de divisão da parcela do ICMS, desconsiderando o IQE, IQS e IQM, fazia com que a maior parcela dos repasses fosse destinado aos municípios de maior escopo geográfico, populacional e econômico. A redistribuição proposta na Lei № 14.023/2007 deflagrou um processo de competição entre os municípios para empreender uma melhor gestão pública, sendo recompensados aqueles com melhor desempenho. Esta abordagem está alinhada aos objetivos da Gestão Pública por Resultados, em que o Estado deve atender aos anseios sociais por eficiência, eficácia e efetividade na execução de políticas públicas.

Com o ICMS Socioambiental ${ }^{2}$, sendo esta a versão cearense do ICMS Ecológico, o Ceará insere-se no rol dos estados que buscam estimular as boas práticas na gestão ambiental municipal. A Tabela 1 lista os dezesseis Estados que possuem o ICMS Ecológico instituído e os respectivos critérios de divisão.

Tabela 1: ICMS Ecológico no Brasil.

\begin{tabular}{|c|c|c|c|}
\hline Estado & $\begin{array}{l}\text { Ano de } \\
\text { Criação }\end{array}$ & Critério & $\begin{array}{l}\text { Participação } \\
\text { (\%) }\end{array}$ \\
\hline \multirow{2}{*}{ Paraná } & \multirow{2}{*}{1991} & Unidades de conservação ambiental & 2,50 \\
\hline & & Mananciais de abastecimento público & 2,50 \\
\hline \multirow{2}{*}{ São Paulo } & \multirow{2}{*}{1993} & Reservatórios de água destinados à geração de energia elétrica & 0,50 \\
\hline & & Unidades de conservação ambiental & 0,50 \\
\hline \multirow{2}{*}{ Minas Gerais } & \multirow{2}{*}{1995} & Sistema de tratamento de lixo e/ou esgoto sanitário & 0,50 \\
\hline & & Unidades de conservação ambiental & 0,50 \\
\hline Rondônia & 1996 & Unidades de conservação ambiental & 5,00 \\
\hline Amapá & 1996 & Unidades de conservação ambiental & 1,40 \\
\hline Rio Grande do Sul & 1998 & Unidades de conservação ambiental e áreas inundadas por barragens & 7,00 \\
\hline Mato Grosso & 2000 & Unidades de conservação ambiental e terras indígenas & 5,00 \\
\hline Mato Grosso do Sul & 2000 & $\begin{array}{l}\text { Unidades de conservação ambiental, terras indígenas } \\
\text { e mananciais de abastecimento público }\end{array}$ & 5,00 \\
\hline \multirow{2}{*}{ Pernambuco } & \multirow{2}{*}{2000} & Mananciais de abastecimento público & 1,00 \\
\hline & & Unidades de compostagem e aterros sanitários & 5,00 \\
\hline \multirow{5}{*}{ Tocantins } & \multirow{5}{*}{2002} & Unidades de conservação ambiental e terras indígenas & 2,00 \\
\hline & & Política municipal de meio ambiente & 1,50 \\
\hline & & Controle e combate a queimadas & 1,50 \\
\hline & & Conservação dos solos & 1,50 \\
\hline & & Saneamento básico e conservação da água & 2,00 \\
\hline Acre & 2004 & Unidades de conservação ambiental & 5,00 \\
\hline \multirow{3}{*}{ Rio de Janeiro } & \multirow{3}{*}{2007} & Unidades de conservação ambiental & 1,13 \\
\hline & & Qualidade da água & 0,75 \\
\hline & & Coleta e disposição adequada de resíduos sólidos & 0,62 \\
\hline Ceará & 2008 & Índice municipal de qualidade do meio ambiente & 2,00 \\
\hline Piauí & 2008 & Selo ambiental & 5,00 \\
\hline Goiás & 2011 & $\begin{array}{l}\text { Unidades de conservação ambiental e mananciais } \\
\text { de abastecimento público }\end{array}$ & 5,00 \\
\hline \multirow{2}{*}{ Paraíba } & \multirow{2}{*}{2011} & Unidades de conservação ambiental & 5,00 \\
\hline & & Coleta e tratamento de lixo domiciliar & 5,00 \\
\hline Pará & 2012 & Unidades de conservação ambiental e gestão ambiental dos municípios & 8,00 \\
\hline
\end{tabular}

Fonte: Carneiro et al. (2018).

De acordo com a Tabela 1, a unidade de conservação ambiental foi o principal critério de repartição do ICMS Ecológico no país, sendo utilizado por quatorze Estados. Em segunda posição, coloca-se o abastecimento e qualidade da água, que foram empregados por sete estados. Embora em pequeno número 
(Minas Gerais, Rio de Janeiro, Pernambuco, Ceará e Paraíba), o manejo dos resíduos sólidos também foi considerado como um critério para a repartição do ICMS Ecológico³.

No Ceará, os critérios metodológicos do IQM foram regulamentados pelos Artigos 18 e 19 do Decreto no 29.306/2008, resultando em valores binários, sendo 1 para o município que atendesse a todos os critérios e 0 se não atendesse ou apenas de maneira parcial aos critérios.

No ano seguinte, mediante Decreto $n^{\circ} 29.881 / 2009$, foi instituído o Formulário $18^{4}$, que estabeleceu os seguintes critérios para qualificação do IQM: I - Implantação da Estrutura Operacional; II - Implantação da coleta sistemática; III - Implantação da coleta seletiva; IV - Apresentação da Licença de Instalação válida para a disposição final dos resíduos sólidos urbanos, preferencialmente consorciada; e $\mathrm{V}$ - Apresentação de Licença de Operação válida para a disposição final dos resíduos sólidos urbanos (CEARÁ, 2009).

O Decreto Estadual $n^{\circ} 32.483 / 2017$ estabeleceu que os consortes passariam a ter acesso aos recursos oriundos do ICMS Socioambiental, por meio do IQM, ao preencher Formulário 18-A, que voltou a ser binário, considerando os seguintes critérios: I - Constituição do consórcio público para gestão integrada de resíduos sólidos e definição da legislação uniforme para a gestão; II - Formação da diretoria do consórcio; III - Criação do fundo específico de meio ambiente que recepcionará o recurso do ICMS sócio ambiental; IV Aprovação do plano regionalizado de coletas seletivas múltiplas; e, V - Afetação do uso de uma ou mais áreas para Central Municipal de Resíduos.

De acordo com os critérios estabelecidos pelo Formulário 18-A, verifica-se que o cerne é a gestão regionalizada dos resíduos sólidos por meio dos consórcios intermunicipais, o que vem a coadunar com o proposto pela Política Estadual de Resíduos Sólidos, mediante Lei Estadual №16.032/2016, que estabelece prioridade no acesso aos incentivos ambientais a municípios que estejam consorciados nesse intuito, além de que uma de suas metas é ter $20 \%$ dos municípios, até 2020 , fazendo parte de algum consórcio público para gestão de resíduos.

\section{MATERIAIS E MÉTODOS}

O território - destacado na Figura 1 - possui área geográfica de $11.347 \mathrm{~km}^{2}$, abrange treze municípios, que formam o Consórcio Integrado dos Resíduos Sólidos do Vale do Jaguaribe (CGIRS-VJ). Porém, para esse estudo, como o ingresso de Jaguaruana e Itaiçaba só veio a ocorrer em 2019, esses municípios não fizeram parte da amostra.

Para esse estudo, adotou-se a série histórica das notas do IQM dos municípios do CGIRS-VJ, no intervalo de 2009 a 2017 (dados disponibilizados pelo Instituto de Pesquisa e Estratégia Econômica do Ceará - IPECE e pela Secretaria Estadual de Meio Ambiente - SEMA). Desconsiderou-se a nota obtida no ano de 2018, face a escolha desses municípios em aderir ao Formulário 18-A, nesse ano.

\footnotetext{
${ }^{3}$ De acordo com Altoé et al. (2019), o termo saneamento básico pode também englobar as atividades inerentes aos resíduos sólidos.

${ }^{4} \mathrm{~A}$ nota do IQM, quando calculada por meio do Formulário 18, variava em função do peso de cada um dos critérios, que, ao longo do tempo, sofreu alguma variação, exceto o item $\mathrm{V}$ - Apresentação de Licença de Operação válida para a disposição final dos resíduos sólidos urbanos 


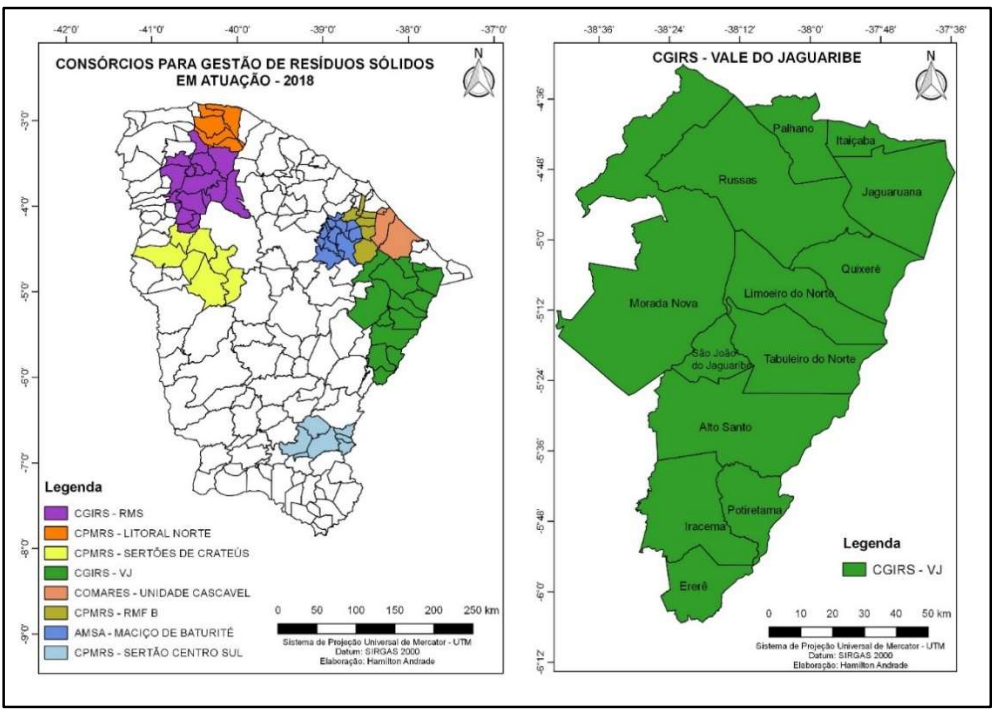

Figura 1: Mapa de localização do CGIRS-VJ.

O método de análise deste estudo abrange as estatísticas descritivas da série temporal do IQM, abrangendo o período 2009-2018, e o modelo de regressão KNN (k-nearest neighbors). A estatística descritiva do IQM é realizada com base nos valores mínimo e máximo, média, mediana, desvio padrão e coeficiente de variação. Utilizam-se também a representação tabular e gráfica para a exposição de relações entre variáveis.

O método $k$-Nearest-Neighbour (KNN) é utilizado para realizar a análise da série temporal não paramétrica e fazer as previsões dos valores do IQM num período de 30 anos, contando a partir de 2018 . 0 algoritmo kNN, por causa de sua simplicidade e fácil compreensão, é amplamente utilizado para classificação e regressão. A aplicação do kNN para previsão de séries temporais sob condição de regressão ponderada localmente foi apresentada independentemente por Yakowitz (1987) e Cleveland (1979).

O algoritmo kNN aplicado a séries temporais univariadas pressupõe que processos consistentes de geração de dados produzem observações de padrões repetitivos do comportamento. Numa série temporal, se um padrão passado puder ser identificado como similar ao comportamento corrente, o comportamento subsequente do padrão passado pode oferecer informação valiosa para prever o comportamento no futuro imediato. Assim, para prever um valor futuro, o algoritmo identifica $\mathrm{k}$ padrões passados mais similares e combina seus valores futuros para fazer a previsão do futuro.

Os procedimentos computacionais e análises estatísticas foram feitos utilizando pacote estatístico $R$ Versão 3.4.3.

\section{RESULTADOS E DISCUSSÃO}

Entre 2008 e 2010, foram instituídos 22 consórcios municipais no Ceará, dos quais, em 2018, oito deles se encontravam com suas Secretarias Executivas constituídas, possuindo desde 3 a 18 entes consorciados, envolvendo 64 municípios (34,8\%). A Tabela 2 apresenta os resultados da avaliação do IQM para cada um dos municípios dos oito Consórcios, em 2018. 
Tabela 2: Resultado final do IQM 2018 por entes consorciados.

\begin{tabular}{|c|c|c|}
\hline Consórcio & Município & Nota \\
\hline \multirow{3}{*}{ CGIRS-RMS } & $\begin{array}{l}\text { Alcântaras, Coreaú, Frecheirinha, Groaíras, Moraújo, Pacuja, } \\
\text { Santana do Acaraú, Senador Sá, }\end{array}$ & 0 \\
\hline & Meruoca $^{5}$ & 0,9 \\
\hline & Cariré, Forquilha, Graça, Massapê, Sobral, Pires Ferreira, Varjota, Reriutaba & 1 \\
\hline Metropolitana B & Chorozinho, Pacajús, Horizonte, Ocara, Guaiúba, Itaitinga & 1 \\
\hline Maciço de Baturité & $\begin{array}{l}\text { Acarape, Aracoiaba, Aratuba, Barreira, Baturité, Capistrano, } \\
\text { Guaramiranga, Itapiúna, Mulungu, Pacoti, Palmácia, Redenção }\end{array}$ & 1 \\
\hline \multirow{2}{*}{ Sertão Centro Sul } & Umari & 0 \\
\hline & Baixio, Grangeiro, Lavras da Mangabeira, Ipaumirim, Cedro, Várzea Alegre & 1 \\
\hline Sertão de Crateús & $\begin{array}{l}\text { Ipueiras, Catunda, Hidrolândia, Ipu, Monsenhor Tabosa, Nova Russas, } \\
\text { Tamboril }\end{array}$ & 1 \\
\hline Cascavel & Bebribe, Cascavel, Pindoretama & 1 \\
\hline Litoral Norte & Acaraú, Cruz, Bela Cruz, Marco, Morrinhos & 1 \\
\hline \multirow[b]{2}{*}{ CGIRS-VJ } & Palhano & 0 \\
\hline & $\begin{array}{l}\text { Alto Santo, Ererê, Iracema, Limoeiro do Norte, Morada Nova, } \\
\text { Potiretama, Quixeré, Russas, São João do Jaguaribe, Tabuleiro do Norte }\end{array}$ & 1 \\
\hline
\end{tabular}

Fonte: SEMA (2018).

Em cinco deles, todos os municípios obtiveram valor máximo do IQM: Metropolitana B, Maciço de Baturité, Sertão de Crateús, Cascavel e Litoral Norte. O total de municípios passível de aderir ao Formulário 18-A somava 64, dos quais 62 (96,9\%) deles o fizeram. Destes, 57 (86,1\%) atingiram a nota máxima. Destacase que 2018 foi o ano em que mais municípios cearenses atingiram nota máxima no IQM.

Tal cenário difere-se significativamente dos anos iniciais do programa. Em 2009, nenhum município cearense conseguiu pontuar; em $2010,87,5 \%$ dos municípios atingiram nota igual ou inferior a 0,2; e, em 2012, a maior parte dos municípios não ultrapassou 0,6 (CONCEIÇÃO et al., 2010; SOUSA; BRAGA, 2014).

Baixas notas do IQM foram uma constante nos municípios entes do CGIRS-VJ, entre os anos 2009 a 2017. A saber, as maiores médias para esse período foram obtidas por Russas, Morada Nova, Tabuleiro do Norte e Quixeré. O maior valor do IQM foi 0,7, obtido por Russas, Morada Nova, Limoeiro do Norte e Tabuleiro do Norte. Os demais obtiveram IQM inferiores a 0,3, tendo Potiretama obtido a menor média, vide estatística descritiva, presente na Tabela 3.

Tabela 3: Estatística descritiva do IQM no período 2009-2017.

\begin{tabular}{|c|c|c|c|c|}
\hline Município & Mínimo & Máximo & Média & $\begin{array}{l}\text { Coeficiente de } \\
\text { Variação (\%) }\end{array}$ \\
\hline Alto Santo & 0,00 & 0,30 & 0,12 & 64,7 \\
\hline Ererê & 0,00 & 0,40 & 0,2 & 72,2 \\
\hline Iracema & 0,10 & 0,40 & 0,2 & 43,5 \\
\hline Limoeiro do Norte & 0,00 & 0,70 & 0,3 & 72,4 \\
\hline Morada Nova & 0,20 & 0,70 & 0,4 & 55,3 \\
\hline Palhano & 0,00 & 0,40 & 0,3 & 21,7 \\
\hline Potiretama & 0,00 & 0,20 & 0,1 & 81,8 \\
\hline Quixeré & 0,20 & 0,50 & 0,3 & 32,3 \\
\hline Russas & 0,10 & 0,70 & 0,4 & 51,1 \\
\hline São João do Jaguaribe & 0,10 & 0,40 & 0,2 & 45,8 \\
\hline Tabuleiro do Norte & 0,10 & 0,70 & 0,4 & 61,1 \\
\hline
\end{tabular}

${ }^{5}$ Mesmo estando consorciado ao CGIRS-RMS, o município de Meruoca optou por aderir ao Formulário 18. 
Constata-se elevada variabilidade nas notas dos consortes, cujos maiores Coeficientes de Variação (CV) foram os de Potiretama ( $\mathrm{CV}=81,8 \%)$, Limoeiro do Norte (CV = 72,4\%) e Ererê (CV = 72,2\%), ao passo que Palhano obteve a menor (CV $=21,7 \%)$.

A alta variabilidade do IQM pode estar associada: à baixa capacidade dos municípios de manter continuamente programas de gestão ambiental; as mudanças nos pesos dos critérios ao longo dos anos; e/ou à incapacidade de atender aos critérios postos no Formulário 18.

Esse fato pode ter promovido implicações negativas para o repasse do ICMS Socioambiental para os municípios consortes, já que seu valor depende da nota do IQM, além da própria arrecadação do Estado e da quantidade de municípios que participam e pontuam.

Nogueira et al. (2013), analisando a consistência no repasse do IQM, contataram que o repasse do ICMS Socioambiental, através do Formulário 18, poderia estar privilegiando os municípios que já possuíam, no início do programa, melhores condições socioeconômicas. Por outro lado, os municípios que possuíam economias inexpressivas precisariam dispender esforços financeiros, organizacionais e institucionais consideráveis para aumentar seu desempenho ambiental e concorrer em condições de igualdade com os demais municípios pelos recursos do ICMS Socioambiental.

Destaca-se que, entre 2014 e 2017, cinco municípios obtiveram zero no IQM, em um total de nove observações, sendo eles: Alto Santo (2015/2016); Ererê (2014/2016); Limoeiro do Norte (2017); Palhano (2017); e Potiretama (2014-2016), cujos valores observados (até 2017) e preditos estão na Tabela 4, cujos valores estão arredondados até a primeira casa decimal, como ocorre nos anos anteriores.

Tabela 4: Observações e previsões do IQM, dos entes do CGIRS-VJ.

\begin{tabular}{|c|c|c|c|c|c|c|c|c|c|c|c|}
\hline \multirow{2}{*}{ Ano } & \multicolumn{11}{|c|}{ IQM } \\
\hline & AS & ER & IR & $\mathrm{LN}$ & $\mathrm{MN}$ & $\mathrm{PL}$ & PT & $Q X$ & $\mathrm{RS}$ & SJJ & $\mathrm{TN}$ \\
\hline 2009 & 0,1 & 0.1 & 0.1 & 0.4 & 0.4 & 0.4 & 0.1 & 0.4 & 0.1 & 0.1 & 0.1 \\
\hline 2010 & 0,2 & 0.2 & 0.2 & 0.2 & 0.5 & 0.2 & 0.2 & 0.2 & 0.2 & 0.2 & 0.2 \\
\hline 2011 & 0,2 & 0.2 & 0.2 & 0.2 & 0.2 & 0.2 & 0.2 & 0.2 & 0.2 & 0.2 & 0.2 \\
\hline 2012 & 0.2 & 0.2 & 0.2 & 0.2 & 0.2 & 0.2 & 0.2 & 0.2 & 0.5 & 0.2 & 0.2 \\
\hline 2013 & 0.2 & 0.2 & 0.4 & 0.4 & 0.3 & 0.4 & 0.2 & 0.4 & 0.7 & 0.4 & 0.4 \\
\hline 2014 & 0.3 & 0 & 0.4 & 0.4 & 0.7 & 0.4 & 0 & 0.4 & 0.7 & 0.4 & 0.7 \\
\hline 2015 & 0 & 0.3 & 0.2 & 0.7 & 0.2 & 0.4 & 0 & 0.4 & 0.5 & 0.3 & 0.4 \\
\hline 2016 & 0 & 0 & 0.2 & 0.1 & 0.7 & 0.4 & 0 & 0.5 & 0.5 & 0.3 & 0.4 \\
\hline 2017 & 0.3 & $\begin{array}{l}0.4 \\
\end{array}$ & 0.2 & 0 & 0.2 & 0 & 0.1 & 0.4 & 0.5 & 0.1 & 0.7 \\
\hline 2018 & 0.2 & 0.2 & 0.2 & 0.2 & 0.3 & 0.2 & 0.2 & 0.3 & 0.6 & 0.2 & 0.4 \\
\hline 2019 & 0.2 & 0.2 & 0.3 & 0.3 & 0.5 & 0.3 & 0.2 & 0.3 & 0.6 & 0.2 & 0.5 \\
\hline 2020 & 0.2 & 0.1 & 0.4 & 0.5 & 0.5 & 0.4 & 0.2 & 0.4 & 0.6 & 0.3 & 0.5 \\
\hline 2021 & 0.1 & 0.1 & 0.3 & 0.5 & $\begin{array}{l}0.4 \\
\end{array}$ & 0.4 & 0.1 & 0.4 & 0.5 & 0.4 & 0.5 \\
\hline 2022 & 0.2 & 0.2 & 0.2 & 0.4 & 0.4 & 0.3 & 0.2 & 0.3 & 0.6 & 0.3 & 0.6 \\
\hline 2023 & 0.2 & 0.2 & 0.3 & 0.4 & 0.2 & 0.3 & 0.2 & 0.3 & 0.6 & 0.3 & 0.5 \\
\hline 2024 & 0.2 & 0.2 & 0.4 & 0.1 & 0.3 & 0.3 & 0.2 & 0.4 & 0.6 & 0.2 & 0.4 \\
\hline 2025 & 0.2 & 0.1 & 0.3 & 0.2 & 0.5 & 0.2 & 0.2 & 0.4 & 0.5 & 0.2 & 0.6 \\
\hline 2026 & 0.2 & 0.2 & 0.3 & 0.2 & 0.4 & 0.2 & 0.2 & 0.3 & 0.6 & 0.2 & 0.6 \\
\hline 2027 & 0.2 & 0.2 & 0.3 & 0.3 & 0.3 & 0.3 & 0.2 & 0.3 & 0.6 & 0.3 & 0.6 \\
\hline 2028 & 0.2 & 0.2 & 0.3 & 0.5 & 0.3 & 0.4 & 0.2 & 0.4 & 0.6 & 0.4 & 0.5 \\
\hline 2029 & 0.2 & 0.2 & 0.3 & 0.5 & 0.3 & $\begin{array}{l}0.4 \\
\end{array}$ & 0.1 & 0.4 & 0.5 & 0.3 & 0.5 \\
\hline 2030 & 0.2 & 0.1 & 0.3 & 0.4 & 0.5 & 0.3 & 0.2 & $\begin{array}{l}0.3 \\
\end{array}$ & 0.6 & 0.3 & 0.5 \\
\hline 2031 & 0.2 & 0.2 & 0.3 & 0.4 & 0.4 & 0.3 & 0.2 & 0.3 & 0.6 & 0.2 & 0.6 \\
\hline 2032 & 0.2 & 0.2 & 0.3 & 0.3 & 0.4 & 0.3 & 0.2 & 0.3 & 0.6 & 0.2 & 0.5 \\
\hline 2033 & 0.2 & 0.2 & 0.3 & 0.2 & 0.3 & 0.2 & 0.2 & 0.4 & 0.6 & 0.2 & 0.5 \\
\hline 2034 & 0.2 & 0.2 & 0.3 & 0.2 & 0.6 & 0.2 & 0.2 & 0.3 & 0.6 & 0.3 & 0.5 \\
\hline
\end{tabular}




\begin{tabular}{|c|c|c|c|c|c|c|c|c|c|c|c|}
\hline 2035 & 0.2 & 0.2 & 0.3 & 0.3 & 0.3 & 0.3 & 0.2 & 0.3 & 0.6 & 0.3 & 0.5 \\
\hline 2036 & 0.2 & 0.1 & 0.3 & 0.5 & 0.5 & 0.4 & 0.1 & 0.4 & 0.6 & 0.4 & 0.5 \\
\hline 2037 & 0.2 & 0.1 & 0.3 & 0.5 & 0.3 & 0.4 & 0 & 0.4 & 0.6 & 0.3 & 0.6 \\
\hline 2038 & 0.1 & 0.2 & 0.3 & 0.3 & 0.3 & 0.3 & 0 & 0.3 & 0.5 & 0.3 & 0.5 \\
\hline 2039 & 0.1 & 0.2 & 0.3 & 0.1 & 0.4 & 0.2 & 0.1 & 0.3 & 0.6 & 0.2 & 0.5 \\
\hline 2040 & 0.2 & 0.3 & 0.3 & 0.2 & 0.5 & 0.2 & 0.2 & 0.4 & 0.6 & 0.2 & 0.6 \\
\hline 2041 & 0.2 & 0.2 & 0.3 & 0.3 & 0.4 & 0.3 & 0.2 & 0.3 & 0.6 & 0.3 & 0.5 \\
\hline 2042 & 0.2 & 0.2 & 0.3 & 0.4 & 0.4 & 0.4 & 0.2 & 0.3 & 0.6 & 0.3 & 0.5 \\
\hline 2043 & 0.2 & 0.1 & 0.3 & 0.5 & 0.3 & 0.4 & 0.1 & 0.3 & 0.6 & 0.3 & 0.5 \\
\hline 2044 & 0.2 & 0.2 & 0.3 & 0.4 & 0.4 & 0.4 & 0.1 & 0.4 & 0.6 & 0.4 & 0.5 \\
\hline 2045 & 0.2 & 0.2 & 0.3 & 0.3 & 0.5 & 0.3 & 0.2 & 0.4 & 0.6 & 0.3 & 0.6 \\
\hline 2046 & 0.2 & 0.2 & 0.3 & 0.3 & 0.4 & 0.3 & 0.2 & 0.3 & 0.6 & 0.2 & 0.5 \\
\hline 2047 & 0.2 & 0.2 & 0.3 & 0.2 & 0.4 & 0.2 & 0.2 & 0.3 & 0.6 & 0.2 & 0.5 \\
\hline
\end{tabular}

Nota: AS - Alto Santo; ER - Ererê; IR - Iracema; LN - Limoeiro do Norte; MN - Morada Nova; PL - Palhano; PT Potiretama; QX - Quixeré; RS - Russas; SJJ - São João do Jaguaribe; TN - Tabuleiro do Norte.

De acordo com a Tabela 5, é possível inferir que a média do IQM para os anos previstos variou entre 0,2, em Alto Santo, Ererê e Potiretama e 0,6, em Russas, similar aos seus respectivos valores máximos, os quais variaram no intervalo entre 0,2 a 0,7 , bem aquém da nota máxima $(1,0)$, obtida por 10 municípios no ano de 2018.

Tabela 5: Estatística descritiva das previsões do IQM, entre 2018 e 2048.

\begin{tabular}{lllll}
\hline Município & Mínimo & Máximo & Média & $\begin{array}{l}\text { Coeficiente de } \\
\text { Variação (\%) }\end{array}$ \\
\hline Alto Santo & 0,1 & 0,2 & 0,2 & 0,31 \\
\hline Ererê & 0,1 & 0,3 & 0,2 & 0,39 \\
\hline Iracema & 0,2 & 0,4 & 0,3 & 0,20 \\
\hline Limoeiro do Norte & 0,1 & 0,5 & 0,3 & 0,43 \\
\hline Morada Nova & 0,2 & 0,7 & 0,4 & 0,31 \\
\hline Palhano & 0,2 & 0,4 & 0,3 & 0,30 \\
\hline Potiretama & 0 & 0,2 & 0,2 & 0,44 \\
\hline Quixeré & 0,3 & 0,4 & 0,3 & 0,18 \\
\hline Russas & 0,5 & 0,6 & 0,6 & 0,21 \\
\hline São João do Jaguaribe & 0,2 & 0,4 & 0,3 & 0,29 \\
\hline Tabuleiro do Norte & 0,4 & 0,6 & 0,5 & 0,24 \\
\hline
\end{tabular}

Este resultado demonstra que o consorciamento, precedido da substituição do Formulário 18 pelo Formulário 18-A, pode proporcionar avanços na gestão ambiental dos municípios, especialmente no tocante ao maior repasse de recursos e, consequente, maior capacidade da promoção de melhorias na gestão de resíduos. De acordo com Limoeiro do Norte (2018), a expectativa é que cada ente consorciado que atingiu nota máxima no IQM 2018, venha a receber um valor estimado de $\mathrm{R} \$ 430.000,00$, em 2019, totalizando cerca de $\mathrm{R} \$ 4,3$ milhões. Esse valor supera em $57,5 \%$ o maior repasse do ICMS Socioambiental, $\mathrm{R} \$ 2,73$ milhões, relativo ao exercício de 2015, conforme Figura 2.

Esse incremento no repasse representa ganhos significativos no orçamento municipal, especificamente nos Fundos Municipais de Meio Ambiente, responsáveis por recepcionar o recurso, o que possibilita investimentos consideráveis em gestão ambiental na região.

Salienta-se que o recurso é recepcionado no Fundo Geral e, só depois, é feita transferência ao Fundo Municipal de Meio Ambiente dos municípios, metodologia que se repete no vizinho estado do Piauí (OLIVEIRA JUNIOR et al., 2019). 


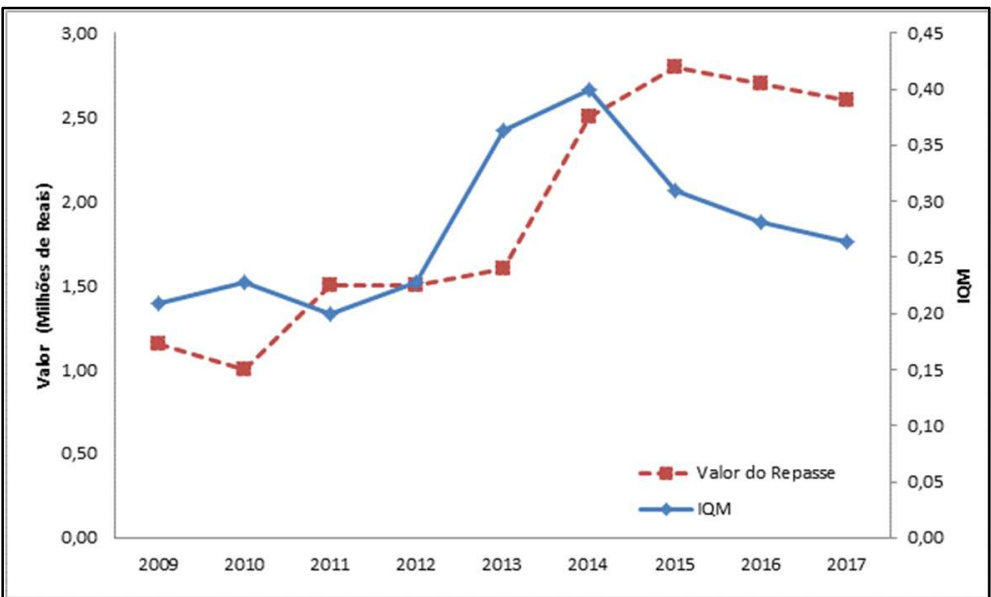

Figura 2: Valor global repassado pelo ICMS Socioambiental aos entes do CGIRS-VJ e média das notas do IQM. Fonte: Adaptado da SEMA (2018)

Porém, vale a pena salientar que o repasse oriundo do IQM deve atender, no mínimo, às ações previstas no Plano Regionalizado de Coleta Seletiva Múltipla, que abrange esses municípios. Até 2020, consta, por exemplo, a necessidade de se contratar estudo de roteirização para a coleta sistemática dos municípios (CGIRS-VJ, 2018).

Esses resultados demonstram que a manutenção das condições existentes no período 2009-2017 impediria que os municípios membros do CGIRS-VJ alcançassem o valor máximo do IQM. Portanto, a criação de incentivos e a revisão periódica dos critérios do IQM tornam-se essenciais para a consolidação da política do ICMS Socioambiental no planejamento da gestão ambiental nos municípios no Estado do Ceará.

\section{CONCLUSÕES}

Este artigo analisou a evolução do Índice Municipal de Qualidade do Meio Ambiente (IQM) dos municípios membros do Consórcio de Gestão Integrada dos Resíduos Sólidos do Vale do Jaguaribe (CGIRSVJ), utilizado como instrumento para o repasse do ICMS Socioambiental no Estado do Ceará.

Os resultados mostraram que, em geral, o IQM foi baixo para os municípios do CGIRS-VJ, entre os anos 2009 e 2017, apresentando elevada variabilidade, quando medidos pelo coeficiente de variação. Essa alta variabilidade do IQM pode estar associada à baixa capacidade dos municípios de manter continuamente programas de gestão ambiental, representado pelas nove observações com valor igual a zero no período investigado, cujas previsões entre o ano de 2018 a 2048 apontam médias variando entre 0,2 a 0,6.

Logo, o fato de estarem consorciados e, por conseguinte, utilizar o Formulário 18-A para acessar o IQM, pode representar melhorias para os municípios, principalmente no que tange ao repasse derivado desse índice, já que o valor global arrecadado será o maior da história, da região, e pelo fato de que o repasse será realizado em uma conta específica do Fundo Municipal de Meio Ambiente. É possível inferir que a gestão ambiental da região acaba de entrar em uma nova era. Tal feito proporcionará maior capacidade de investimento na gestão ambiental municipal.

Além disso, os novos critérios de análise, presentes no Formulário 18-A, servirão para estimular a adesão de mais municípios à participação em consórcios intermunicipais de Gestão Integrada de Resíduos 
Sólidos, visto que é mais favorável a obtenção de melhores resultados junto ao IQM.

\section{REFERÊNCIAS}

ALTOÉ, L.; OLIVEIRA FILHO, D.; COSTA, J. M.; CARLO, J. C.; MARTINEZ, F. J. R.; GRACIA, L. M. N.. Panorama, desafios e oportunidades do ICMS ecológico no Brasil. Revista Gestão \& Sustentabilidade Ambiental, Florianópolis, v.8, n.4, p.403419, 2019. DOI:

http://dx.doi.org/10.19177/rgsa.v8e42019403-419

CARNEIRO, A. F.; CHINCOVIAKI, A. P.; VIDIGAL FILHO, A. L.. ICMS Ecológico nas Finanças dos Municípios de Rondônia. Brazilian Applied Sciense Review, v.2, p.458-477, 2018.

CEARÁ. Lei n. 12.612, de 7 de agosto de 1996. Define, na forma do Art. 158, Parágrafo Único, II, da Constituição Federal, critérios para distribuição da parcela de receita do produto de arrecadação do ICMS pertencente aos municípios. Fortaleza: DOE, 1996.

CEARÁ. Decreto n. 29.306, de 05 de junho de 2008. Dispõe sobre os critérios de apuração dos índices percentuais destinados à entrega de $25 \%$ (vinte e cinco por cento) do ICMS pertencente aos municípios, na forma da Lei n. 12.612, de 7 de agosto de 1996, alterada pela lei no14.023, de 17 de dezembro de 2007, e dá outras providências. Fortaleza: DOE, 2008.

CEARÁ. Decreto n. 29.881, de 31 de agosto de 2009. Altera dispositivos do decreto n. 29.306, de 05 de junho de 2008, e dá outras providências. Fortaleza: DOE, 2009.

CEARÁ. Decreto n. 32.482, de 08 de dezembro de 2017. Altera o Decreto n. 29.306, de 05 de junho de 2008, e dá outras providências. Fortaleza: DOE, 2017.

CEARÁ. Lei n. 14.023, de 17 de dezembro de 2007. Modifica dispositivos da Lei n. 12.612, de 7 de agosto de 1996, que define critérios para distribuição da parcela de receita do produto e arrecadação do Imposto Sobre Operações Relativas à Circulação de Mercadorias e sobre Prestações de Serviços de Transporte Interestadual e Intermunicipal e de Comunicação - ICMS, pertencente aos municípios e dá outras providências. Fortaleza: DOE, 2007.

CEARÁ. Secretaria do Meio Ambiente. Plano Regional de Gestão Integrada de Resíduos Sólidos: Região Médio Jaguaribe. Fortaleza: DOE, 2018.

CLEVELAND, W. S.. Robust locally weighted regression and smoothing scatterplots. Journal of the American Statistical Association, v.74, n.368, p.67-83, 2002.

CONCEIÇÃO, M. G.; GOMES, S. M. S.; OLIVEIRA, N. C.; OLIVEIRA, N. S.; AZEVEDO, T. C.. Adoção do ICMS ecológico nos estados da região nordeste e os critérios de repasse para os municípios. Revista Brasileira de Contabilidade, v.205, p.47-62, 2010.

COSTA, N. G. G.; RAULINO, A R. S.. Extrafiscalidade como instrumento de implementação das políticas públicas: ICMS ecológico e IVA social. Revista de Direito Tributário e Financeiro, Curitiba, v.2, n.2, p.289-309, 2016. DOI: 10.26668/IndexLawJournals/2526-0138/2016.v2i2.1370
FERREIRA, S.; SIQUEIRA, J.; MACEDO, M.. ICMS ecológico e preservação ambiental: uma análise da evolução do quociente entre a dotação atualizada da rubrica gestão ambiental e o orçamento atualizado dos municípios da Zona da Mata de Minas Gerais. Revista de Contabilidade do Mestrado em Ciências Contábeis da UERJ, v.21, n.3, 2017. DOI: https://doi.org/10.12979/26178

LIMA, M. V. F.; MACEDO, F. F. R. R.. Influência do ICMS ecológico na sustentabilidade ambiental do estado do Ceará. Revista Controle: Doutrina e Artigos, v.17, n.2, p.177205, 2019. DOI: https://doi.org/10.32586/rcda.v17i2.531

NOGUEIRA, C. A. G.. Efeitos distributivos das políticas públicas: o caso da nova metodologia de cálculo da cota parte do ICMS do Ceará. Revista FSA, v.9, p.53-67, 2012.

NOGUEIRA, C. A. G.; MONTEIRO, M. A. P.; MAZZA, A. C. A. Uma Análise da Consistência do ICMS Ecológico do Ceará Enquanto Mecanismo de Incentivos e de Redistribuição de Recursos Financeiros. Revista Ciências Administrativas, v.19, p.446-475, 2013. DOI: https://doi.org/10.5020/2318$\underline{0722.2013 . v 19 n 2 \mathrm{p} 446}$

OLIVEIRA JUNIOR, M. A. C.; SILVA, L. N.; SILVA, R. L. S.; TEIXEIRA, L. I. L.; SENA, E. M.; ARRUDA, P. C. L.. ICMS Ecológico: uma análise das ações realizadas no município de Piripiri/PI. Somma: Revista Científica do Instituto Federal de Educação, Ciência e Tecnologia do Piauí, Teresina, v.5, n.1, p.80-87, 2019.

ROLIM, F. P. O.; MARINHO, M. A.. Repartição constitucional do ICMS: as potencialidades de proteção ao meio ambiente suscitadas com a publicação da Lei no 9.600/2011 que instituiu o ICMS Ecológico no Estado da Paraíba. Revista de Direito, Cabedelo, v.1, n.1, p.94- 125, 2013.

SEBBAG, E.. Manual de direito tributário. 6 ed. São Paulo: Saraiva, 2014.

SILVA JUNIOR, L. H.; SOBRAL, E. F. M.. O ICMS

Socioambiental de Pernambuco: uma avaliação dos componentes socioeconômicos da política a partir do Processo de Markov. Revista Planejamento e Políticas Públicas, n.42, p.189-217, 2014.

TAKENAKA, E. M. M.; LEPRE, T. R. F.; HUGARO, F. M.. Pagamento por serviços ambientais: apontamentos sobre o ICMS ecológico como instrumento de fomento a políticas públicas ambientais no Brasil. South American Development Society Journal, São Paulo, v.2, n.6, p.83-99, 2016.

TUPIASSU, L.; FADEL, L. P. S. L.; GROS-DESORMEAUX, J.. ICMS Ecológico e desmatamento nos municípios prioritários do estado do Pará. Rev. Direito GV, São Paulo, v.15, n.3, p.e1928, 2019. DOI: https://doi.org/10.1590/2317$\underline{6172201928}$

YAKOWITZ, S.. Nearest-neighbour methods for time series analysis. Journal of Time Series Analyais, v.8, n.2, p.235-247, 1987. DOI: https://doi.org/10.1111/j.14679892.1987.tb00435.x

A CBPC - Companhia Brasileira de Produção Científica (CNPJ: 11.221.422/0001-03) detém os direitos materiais desta publicação. Os direitos referem-se à publicação do trabalho em qualquer parte do mundo, incluindo os direitos às renovações, expansões e disseminações da contribuição, bem como outros direitos subsidiários. Todos os trabalhos publicados eletronicamente poderão posteriormente ser publicados em coletâneas impressas sob coordenação da Sustenere Publishing, da Companhia Brasileira de Produção Científica e seus parceiros autorizados. Os (as) autores (as) posteriormente ser publicados em coletâneas impressas sob coordenação da Sustenere Publishing, da Companhia Brasileira de Produção Científica e seus par
preservam os direitos autorais, mas não têm permissão para a publicação da contribuição em outro meio, impresso ou digital, em português ou em tradução. 